\title{
A diagnostic assessment of the health system's response to FGM/C management and prevention in Nigeria-Brief
}

\author{
Osasuyi Dirisu \\ Population Council \\ Adetayo Adetunji \\ Mayokun Adediran \\ Population Council \\ Otibho Obianwu
}

Follow this and additional works at: https://knowledgecommons.popcouncil.org/departments_sbsr-rh

Part of the Demography, Population, and Ecology Commons, Family, Life Course, and Society Commons, Gender and Sexuality Commons, International Public Health Commons, and the Medicine and Health Commons How does access to this work benefit you? Let us know!

\section{Recommended Citation}

Dirisu, Osasuyi, Adetayo Adetunji, Mayokun Adediran, and Otibho Obianwu. 2020. "A diagnostic assessment of the health system's response to FGM/C management and prevention in Nigeria-Brief," Evidence to End FGM/C: Research to Help Girls and Women Thrive. Nairobi: Population Council. 


\section{A Diagnostic Assessment of the Health System's Response to FGM/C Management and Prevention in Nigeria}

Findings from this study show that the level of readiness of the health facilities to handle FGM/C-related complications is low as evidenced by poor infrastructure, lack of equipment and limited human capacity.

Improving the health system response in the prevention and management of FGM/C complications requires focused funding, political leadership and better stakeholder coordination.
The Evidence to End FGM/C programme consortium generates evidence to inform and influence investments, policies, and programmes for ending female genital mutilation/cutting in different contexts.

Population Council Lead Institution

Africa Coordinating Centre for the Abandonment of

Female Genital Mutilation/Cutting, Kenya (ACCAF)

Global Research and Advocacy Group, Senegal (GRAG)

The Gender and Reproductive Rights

Resource and Advocacy

Centre (GRACe)

Mannion Daniels Ltd. (MD)

Population Reference Bureau (PRB)

University of Washington (Prof. Bettina Shell-Duncan)

University of California, San Diego (Dr. Gerry Mackie)

Funded by

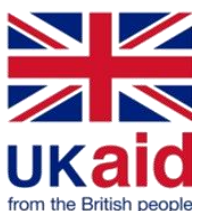

\section{BACKGROUND}

Female genital mutilation (FGM/C), has no health benefits, it violates human rights and has adverse health (physical, psychological, sexual, maternal and child health), and social consequences ${ }^{1,2}$. Globally, over 200 million women have been cut and are living with FGM/C-related consequences ${ }^{3,4}$. In Africa, it is estimated that 27 million, 24 million and 20 million girls/women have undergone FGM/C in Egypt, Ethiopia and Nigeria respectively, making them the countries with the highest prevalence of $F G M / C$ on the continent ${ }^{5}$. In Nigeria, although the practice is considered widespread, national surveys suggest a gradual decline of FGM/C prevalence among women aged $15-49$ years $30 \%$ in 2008 to $20 \%$ in 2018 6,7. While these statistics suggest progress, the prevalence is, however, is still as high as $67 \%$ in some states ${ }^{8}$. Despite the existence of laws, policies and a plan of action that should drive the health system's response to prevention and management of FGM/C, the practice persists. Nigeria's National Strategic Health Development Plan Framework (2009- 2015) highlighted the need to strengthen the health system to cater for an increasing population served by scarce skilled health professionals. The extent of preparedness of health facilities (primary, secondary and tertiary) to prevent and manage complications of $F G M / C$ is poorly understood.

\section{RESEARCH METHODS AND QUESTIONS}

A qualitative approach as well as a health facility assessment was undertaken to understand the health system's response to the management and prevention of FGM/C in Imo state. In-depth interviews, focus group discussions, clinical meetings among service providers, key informant interviews and stakeholder dialogues (national and state level) were used. A health facility assessment was also conducted to examine service delivery levels. The study explored how the health system implements the national policy and plan of action for FGM/C and how the health care sector supports the prevention and management of FGM/C-related complications to identify possible solutions for systems strengthening. Descriptive statistics were used to summarise survey data and qualitative interviews were digitally recorded, transcribed and analysed using NVIVO 12 software. Thematic analysis was used to explore emergent patterns and themes within the data. Ethical approval was obtained from Imo State Ministry of Health and from Population Council's Institutional Review Board (IRB).

The main questions researchers sought to answer were:

- How is the health sector responding to existing FGM/C-related laws and policies?

- What role is the health care sector playing in the prevention of FGM/C? 
- What are contextual stakeholders supporting or inhibiting the health sector's response to FGM/C?

- What is the availability, content, and quality of FGM/C-related service provision?

- How is the health sector catering to the needs of women/girls who have undergone FGM/C?

\section{WHAT THE EVIDENCE SHOWS:}

- Leadership and governance: Limited political will and lack of intersectoral collaboration across different layers of government actors resulted in poor ownership and implementation of the policies and action plans related to the elimination of FGM/C. The role of government in leadership and coordination of FGM/C activities has been further limited by funding gaps within the state.

- Service readiness: FGM/C awareness and prevention services were high at the community level, but the overall level of preparedness of health facilities to respond to $\mathrm{FGM} / \mathrm{C}$ related complications was relatively low as evidenced by poor infrastructure, lack of equipment and poor human capacity.

- Budgeting and funding for FGM/C activities: Serious funding gaps were identified at two levels main levels - poor budgetary provision and poor disbursement. These gaps affect policy dissemination, implementation, and domestication at both the Federal and State levels. The reliance on donor-funding for projects has skewed implementation in favour of donor-priority states and donor-focused activities.

- Health workforce: There are an inadequate number of skilled personnel to provide FGM/Cspecific prevention services and management of complications. The few available personnel have a limited understanding of treatment and management of FGM/c complications.

- Health information system: FGM/C is not documented at health facilities and as a result, incidence and prevalence data are almost nonexistent. This is due to inadequate manpower to capture records, the absence of a column in the facility register to capture $\mathrm{FGM} / \mathrm{C}$ status, and poor knowledge among health workers on the importance.

- Availability of medicines, equipment, and supplies: Medicines, equipment and supplies were inadequate at health facilities. Although this gap is primarily attributable to poor funding, additional factors include weak systems for monitoring/maintaining materials, equipment and supplies in most facilities.

\section{RECOMMENDATIONS}

To strengthen the health system response to $\mathrm{FGM} / \mathrm{C}$ in Nigeria, we recommend that:

- There should be improved data management systems for FGM/C at the facility and community level to help the government better understand the levels of $\mathrm{FGM} / \mathrm{C}$.

- The government should demonstrate financial commitment and ensure transition and ownership of activities beyond the tenure of FGM/C projects. This would strengthen the ownership, coordination and the role of government in the FGM response as well as improve sustainability of FGM/C programs.

- Health workers should be properly trained and sensitized on the WHO guidelines on management of FGM/C complications to improve their capacity to respond.

- Research should be commissioned to explore client satisfaction, quality of care and management of FGM/C complications.

\section{REFERENCES}

1. WHO (2006) Study Group on Female Genital Mutilation and Obstetric Outcome. "Female genital mutilation and obstetric outcome: WHO collaborative prospective study in six African countries." Lancet. 367(9525):1835-1841.

2. Kimani S, Muteshi J and Njue C. (2016). Health Impacts of FGM/C: A Synthesis of the Evidence," Evidence to End FGM/C Programme: Research to Help Girls and Women Thrive. New York: Population Council. http://www.popcouncil.org/EvidencetoEndFGM-C

3. UNICEF (2016). Female Genital Mutilation/ Cutting: A Global Concern: www.data.unicef.org/resources/female-genitalmutilation-cutting-a-global-concern.html

4. UNICEF (2014). "Female Genital Mutilation/Cutting: What might the future hold?" New York.

5. United Nations Children's Fund, \& Gupta, G. R. (2013). Female Genital Mutilation/Cutting: A statistical overview and exploration of the dynamics of change. Reproductive Health Matters, 184190.

6. National Population Commission (NPC) [Nigeria] and ICF International. 2014. Nigeria Demographic and Health Survey 2013. Abuja, Nigeria and Rockville, Maryland, USA: NPC and ICF International.

7. National Population Commission (NPC) [Nigeria] and ICF 2019. Nigeria Demographic and Health Survey 2018. Abuja, Nigeria, and Rockville, Maryland, USA: NPC and ICF.

8. National Bureau of Statistics (NBS) and United Nations Children's Fund (UNICEF) (2017) Multiple Indicator Cluster Survey 2016-17, Survey Findings Report. Abuja, Nigeria: National Bureau of Statistics and United Nations Children's Fund.

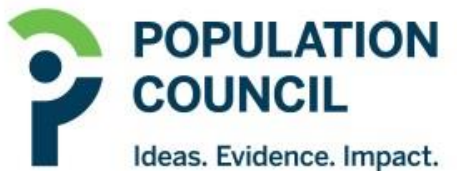

